
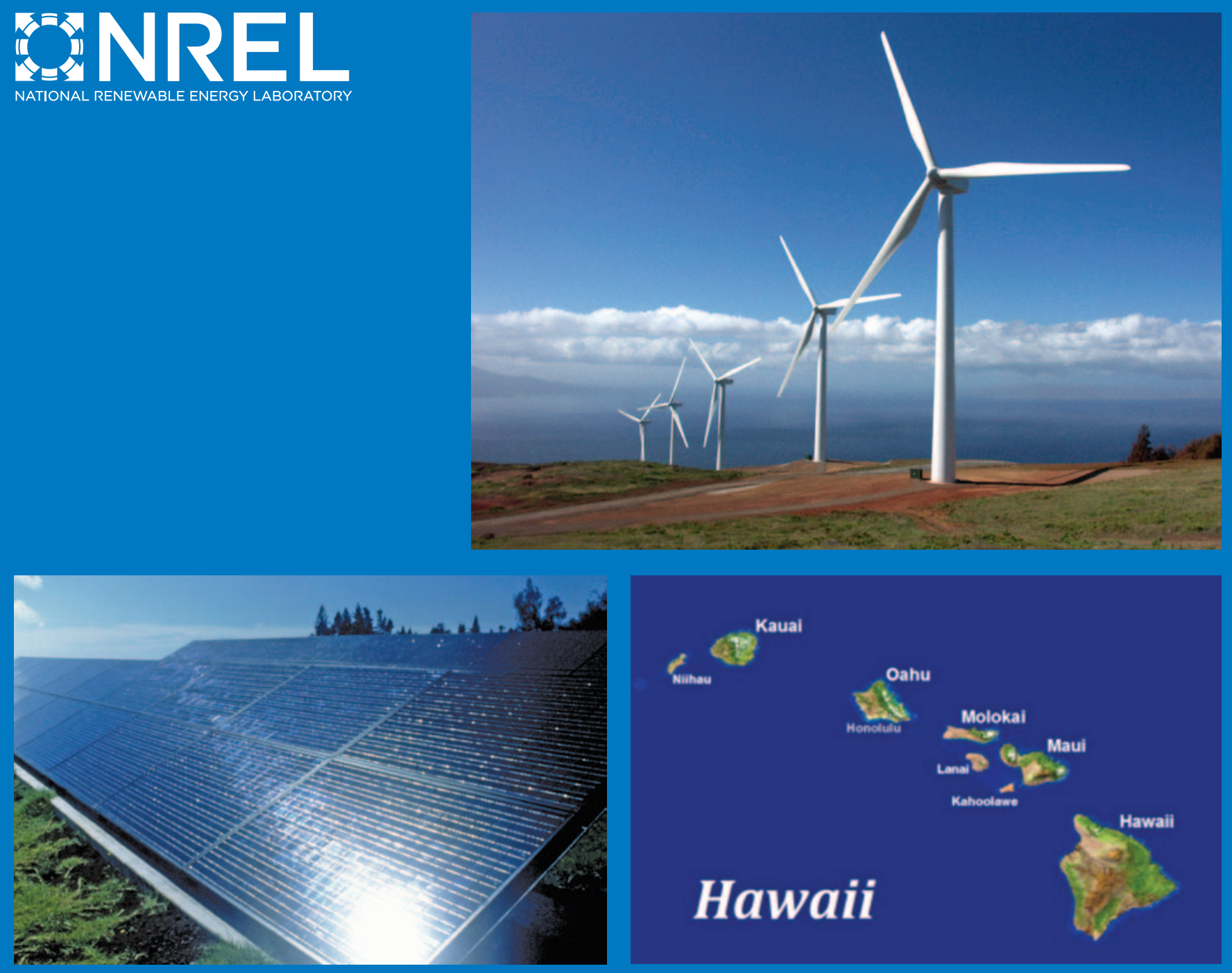

\title{
OAHU WIND INTEGRATION AND TRANSMISSION STUDY: SUMMARY REPORT
}




\section{NOTICE}

This report was prepared as an account of work sponsored by an agency of the United States government. Neither the United States government nor any agency thereof, nor any of their employees, makes any warranty, express or implied, or assumes any legal liability or responsibility for the accuracy, completeness, or usefulness of any information, apparatus, product, or process disclosed, or represents that its use would not infringe privately owned rights. Reference herein to any specific commercial product, process, or service by trade name, trademark, manufacturer, or otherwise does not necessarily constitute or imply its endorsement, recommendation, or favoring by the United States government or any agency thereof. The views and opinions of authors expressed herein do not necessarily state or reflect those of the United States government or any agency thereof.

Available electronically at http:/ / www.osti.gov / bridge

Available for a processing fee to U.S. Department of Energy

and its contractors, in paper, from:

U.S. Department of Energy

Office of Scientific and Technical Information

P.O. Box 62

Oak Ridge, TN 37831-0062

phone: 865.576 .8401

fax: 865.576 .5728

email: mailto:reports@adonis.osti.gov

Available for sale to the public, in paper, from:

U.S. Department of Commerce

National Technical Information Service

5285 Port Royal Road

Springfield, VA 22161

phone: 800.553 .6847

fax: 703.605 .6900

email: orders@ntis.fedworld.gov

online ordering: http:/ / www.ntis.gov/ ordering.htm

Printed with a renewable-source ink on paper containing at least $50 \%$ wastepaper, including $10 \%$ post consumer waste. 


\section{OAHU WIND INTEGRATION AND TRANSMISSION STUDY:} SUMMARY REPORT

November 2010

Dave Corbus' 1 , Matt Schuerger' ${ }^{1}$ Leon Roose2, Josh Strickler ${ }^{3}$, Terry Surles ${ }^{4}$, Devon Manz ${ }^{5}$, Dave Burlingame ${ }^{6}$, and Dennis Woodford7

NREL/TP-5500-48632

\footnotetext{
1 National Renewable Energy Laboratory

2 Hawaiian Electric Company

3 Hawaii Department of Business, Economic Development, and Tourism

4 Formerly with the Hawaii Natural Energy Institute

5 General Electric

6 Electric Power Systems

7 Electranix
} 


\section{ACKNOWLEDGMENTS}

The National Renewable Energy Laboratory (NREL) thanks the Hawaii Electric Company (HECO), the state of Hawaii Department of Business, Economic Development, and Tourism (DBEDT), the Hawaii Natural Energy Institute, and the U.S. Department of Energy (DOE) for supporting and sponsoring OWITS; the Technical Review Committee (TRC) for such great participation and input; and the study team of GE, Electranix, Electric Power Systems (EPS) and AWS Truepower for carrying out the work.

\section{TECHNICAL REVIEW COMMITTEE MEMBERS}

Graeme Ancell

Dean Arakawa, Colton Ching, Dan Giovanni, Marc Matsuura, Dora Nakafuji, Kerstan Wong, Robert Young, Leon Roose

Mike Behnke

Leslie Bryans

Marcey Chang

Dave Corbus, Debbie Lew,

Vahan Gevorgian, Matt Schuerger

Abe Ellis, Ben Karlson

Jay Griffin, Terry Surles

Mathew McNeff

Mark McGranaghan

Mark O'Malley

Dale Osborn

Steve Pullins

Henry Shiu

Charlie Smith

Joshua Strickler

Rich Vandrunen

Bob Zavadil

\section{WORK TEAM MEMBERS}

Devon Manz, Nick Miller, Sebastian Achilles, Gene Hinkle, Reigh Walling, Harjeet Johal

David Burlingame, Jim Cote

Dennis Woodford, Garth Irwin

John Manobianco, Michael Brower
Transpower New Zealand

Hawaiian Electric Company

BEW Engineering

Northern Ireland Electricity

Hawaii Department of Consumer Advocate

National Renewable Energy Laboratory

Sandia National Laboratories

Hawaii Natural Energy Institute

Maui Electric Company

Electric Power Research Institute

University College Dublin

Midwest ISO

Horizon Energy Group

University of California, Davis

Utility Wind Integration Group

Hawaii Department of Business, Economic

Development \& Tourism

State Public Utilities Commission

EnerNex

\author{
General Electric \\ Electric Power Systems \\ Electranix
}

AWS Truepower

Finally, special thanks to Bill Parks and Steve Lindenberg of DOE, Ted Peck and Ted Liu of DBEDT, and Leon Roose of HECO for their continued support for this work and their commitment to HCEI. 


\section{EXECUTIVE SUMMARY}

The Hawaii Clean Energy Initiative (HCEI), which was announced in January 2008, includes an aggressive mandate for the state of Hawaii to generate $40 \%$ of its energy from renewable resources by 2030. To reach this goal, the state will need to develop and utilize a diverse set of renewable energy options including solar, wind, biomass, geothermal, hydropower, and ocean technologies; the $40 \%$ goal can only be met by harnessing different renewable resources in a multi-technology approach. The HCEI agreement specifically identifies up to $400 \mathrm{MW}$ of wind energy from Molokai and Lanai that will be brought to Oahu (the "Big Wind" projects) as part of this diversified portfolio of renewable energy technologies. This Big Wind element of the HCEI agreement is a significant part of the $40 \%$ renewable energy goal.

An important aspect of the Big Wind projects identified in the HCEI agreement is that they require a transmission component to carry the power generated on Molokai and Lanai to Oahu. The favorable wind resources on Molokai and Lanai will be used to generate $400 \mathrm{MW}$ of wind power that is transmitted to Oahu, which has the biggest electrical load, by an undersea electrical cable. As a result, it is necessary to study and implement the Molokai and Lanai wind projects in conjunction with the undersea transmission cable.

Integrating large amounts of variable renewable energy such as wind or solar into an electrical grid is challenging because of the variability of the power output. Previous "wind integration" studies have been performed over the last several years to examine the technical aspects of integrating large amounts of wind power into the bulk electrical grids in the United States and Europe. The methodologies and lessons learned from these studies were applied to the Oahu grid, which is even more challenging because it has a significantly smaller load. This study, the Oahu Wind Integration and Transmission Study (OWITS), was composed of several smaller studies and was sponsored jointly by the Hawaiian Electric Company, the state of Hawaii Department of Business, Economic Development, and Tourism (DBEDT), and the U.S. Department of Energy (DOE). The scope of the OWITS work includes the following:

- Identify the technical requirements and configuration for an undersea inter-island cable to transmit electricity from large wind plants on Molokai and Lanai to Oahu;

- Identify the ancillary services and potential mitigation measures to offset the variable nature of planned wind and solar generation;

- Evaluate potential modifications to the utilities' existing conventional generating units to offset the variable nature of wind and solar energy; and 
- Changing some of the utilities operational practices and procedures, including an evaluation of the potential benefits of wind forecasting, required to operate the island grids with inter-island wind integration.

The scenarios studied in OWITS include $200 \mathrm{MW}$ of wind generation on both Molokai and Lanai with an additional 100 MW of wind and 100 MW of solar generation on Oahu. Small amounts of the Molokai and Lanai wind power will be available to contribute to the small local loads on Molokai and Lanai, but the vast majority of it will be used for the much larger Oahu electrical load. The OWITS scenarios do not include all the solar energy envisioned for Oahu under the HCEI, but rather an amount that could be technically integrated into the study methodology within the budget and timeline of the OWITS project. Future PV integration studies will more specifically address integrating solar energy on Oahu and other Hawaiian Islands by building off the results and methodologies of OWITS.

In January 2009, the National Renewable Energy Laboratory (NREL) convened and facilitated a Technical Review Committee (TRC) for the OWITS studies. The primary focus of the TRC was to provide technical review of the OWITS work including methods, assumptions, and preliminary results. The TRC members were regional, national, and international technical experts with substantial experience in power systems, renewable energy, direct-current (DC) cable systems, island grids, and wind and solar integration. The TRC held five in-person meetings, each two days long, over the project's 18-month period.

The findings of the TRC contain many technical details that describe the complex analysis of the Big Wind component of the HCEI and the undersea cable, as discussed herein and in related reports. These studies (see references 3, 4, and 5) provide a ground-breaking analysis of high renewable penetrations in an island grid system. The conclusion of the TRC analysis of the Big Wind and undersea cable initiatives under the HCEI agreement is that bringing $400 \mathrm{MW}$ of wind to Oahu with an undersea cable, although challenging from both an engineering and environmental permitting aspect, is technically feasible and should be pursued as an important part of the $40 \%$ renewable HCEI goal.

\section{OVERVIEW}

The goal of the Oahu Wind Integration and Transmission Study (OWITS) is to help stakeholders, especially the utility and the state, to 1) understand the costs and operating impacts of significant amounts of wind power-up to 400 megawatts (MW) on Molokai/Lanai and $100 \mathrm{MW}$ on Oahu - on their island grids, and 2) plan for future transmission to accommodate this wind.

The Hawaii Clean Energy Initiative (HCEI) includes the following:

- $40 \%$ renewable generation from clean energy by 2030

( $10 \%$ by $2010,15 \%$ by 2015 , and $25 \%$ by 2020 ), 
- Expanded distributed generation and load reduction,

- Biofuel conversion, and

- Up to $400 \mathrm{MW}$ wind power from Molokai / Lanai to Oahu (the "Big Wind" projects).

A number of studies, driven by specific near-term objectives, have been done that relate to the Hawaiian Electric Company (HECO) Big Wind Study. The scope of the OWITS work includes the following:

- Identifying the technical requirements and configuration for an undersea inter-island cable to transmit electricity from large wind plants to Oahu;

- Identifying the ancillary services and potential mitigation measures to offset the variable nature of planned wind generation;

- Evaluate potential modifications to the utilities' existing generating units to offset the variable nature of wind energy; and

- Changing some of the utilities operational practices and procedures, including an evaluation of the potential benefits of wind forecasting, that are required to operate the island grids with inter-island wind integration.

The four primary projects included in the OWITS listed below are inter-related and have similar data needs:

1. HECO studies-A series of studies to better understand the operating characteristics and limitations of HECO's generating units, the energy management system (EMS), the interaction between the two, and potential changes/ enhancements that can be reasonably assumed for the forward-looking study;

2. Electric Power Systems Inc. (EPS) study—A dynamic stability modeling study of the existing Oahu grid;

3. General Electric (GE)/ Hawaii Natural Energy Institute (HNEI)/HECO studyDevelopment and validation of a forward-looking modeling effort for the Oahu electrical grid with consideration of wind and solar integration; and

4. R.W. Beck and Electranix studies—Studies of various inter-island cable options.

In addition, there has been analysis comparing photovoltaic (PV) and wind, as well as a study on financing the cable project. 


\section{Organization of Study and Technical Review Committee}

The OWITS was sponsored jointly by the Hawaiian Electric Company, the state of Hawaii Department of Business, Economic Development, and Tourism (DBEDT), and the U.S. Department of Energy (DOE); see Figure 1.

In January 2009, the National Renewable Energy Laboratory (NREL) convened and facilitated a Technical Review Committee (TRC) for the OWITS studies. The primary focus of the TRC was technical review of the OWITS study work including methods, assumptions, and preliminary results.

The TRC members were regional, national, and international technical experts with substantial experience in power systems, renewable energy, direct-current (DC) cable systems, island grids, and wind integration. The TRC held five in-person meetings, each two days long, over the project's 18-month period. The meetings were facilitated on a consensus basis and consisted of robust, active discussions of best practices and approaches for these technically challenging studies.

The TRC also reviewed and provided feedback on gaps, overlaps, data needs, and timelines relating to the coordination of the four primary studies. Although the TRC reviewed the studies and made recommendations, the individual project sponsors had final decision-making authority for their projects.

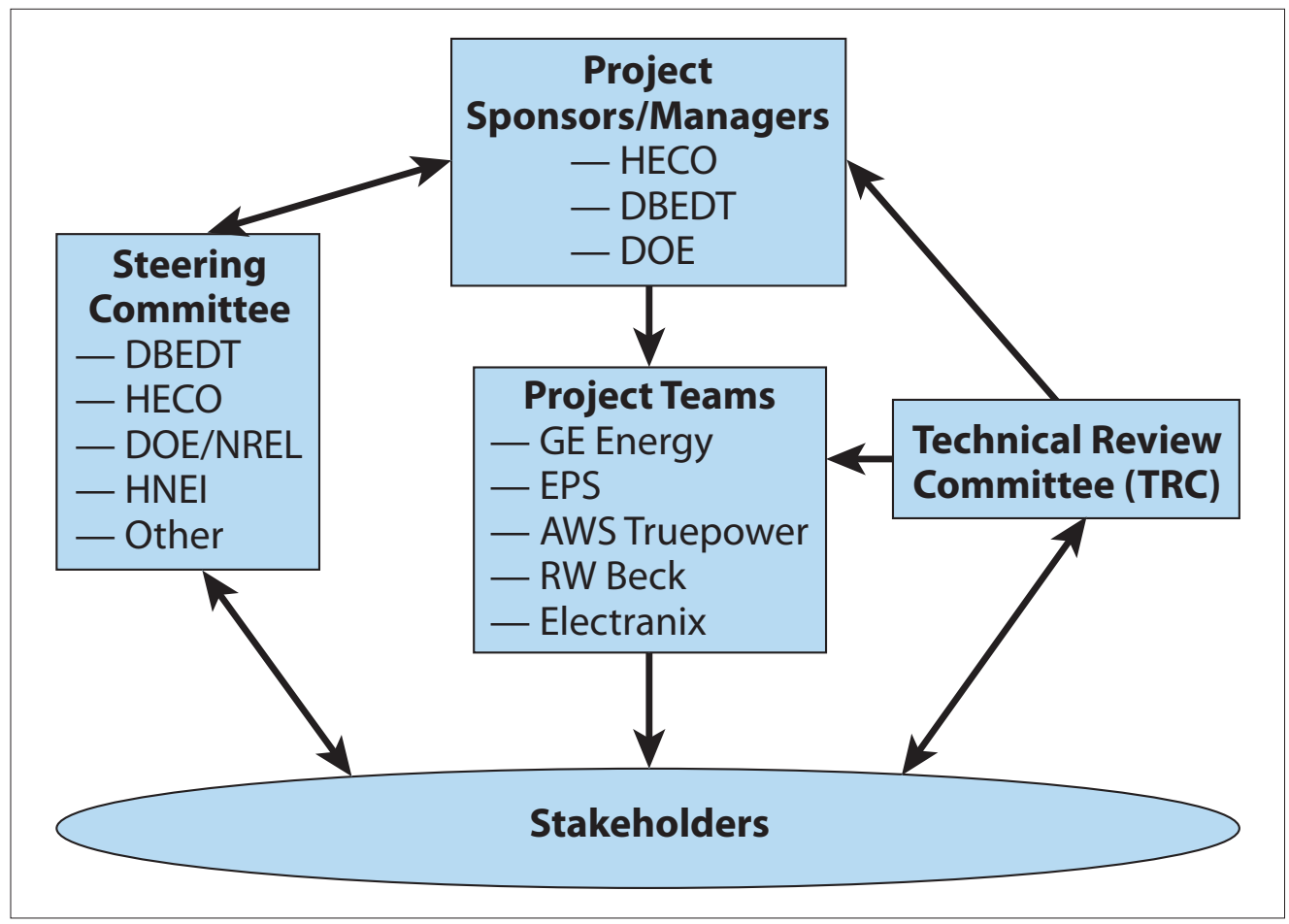

Figure 1. Organization of the OWITS. 


\section{MAJOR TASKS}

The major tasks of OWITS described below include the HCEI Big Wind scenarios, HECO grid background and baseline assessment, the Hawaiian Islands Transmission Interconnection Project, the Oahu Wind Integration Study, and additional tasks.

\section{BIG WIND SCENARIOS FOR HCEI}

Table 1 shows the initial scenario analysis matrix developed by GE and HECO to assess the cable and resource options. This matrix was shared with the TRC in subsequent discussions. Figure 2 provides a map that illustrates the wind and PV scenarios on Oahu, Molokai, and Lanai.

\begin{tabular}{|l|c|c|c|c|}
\hline \multirow{2}{*}{ TABLE 1 - INITIAL BIG WIND SCENARIO ANALYSIS MATRIX } \\
\hline \multirow{2}{*}{ SCENARIO } & \multicolumn{3}{|c|}{ WIND (MW) } & SOLAR (MW) \\
\cline { 2 - 5 } & OAHU & LANAI & MOLOKAI & OAHU \\
\hline 1. OAHU WIND & 100 & & & 100 \\
\hline 2. OFF-ISLAND WIND & 100 & & 200 & \\
\hline 3. CONCENTRATED WIND & 100 & 400 & & 100 \\
\hline 4. OAHU SOLAR & & & & 100 \\
\hline 5. HIGH RENEWABLES & 100 & 200 & 200 & 100 \\
\hline
\end{tabular}

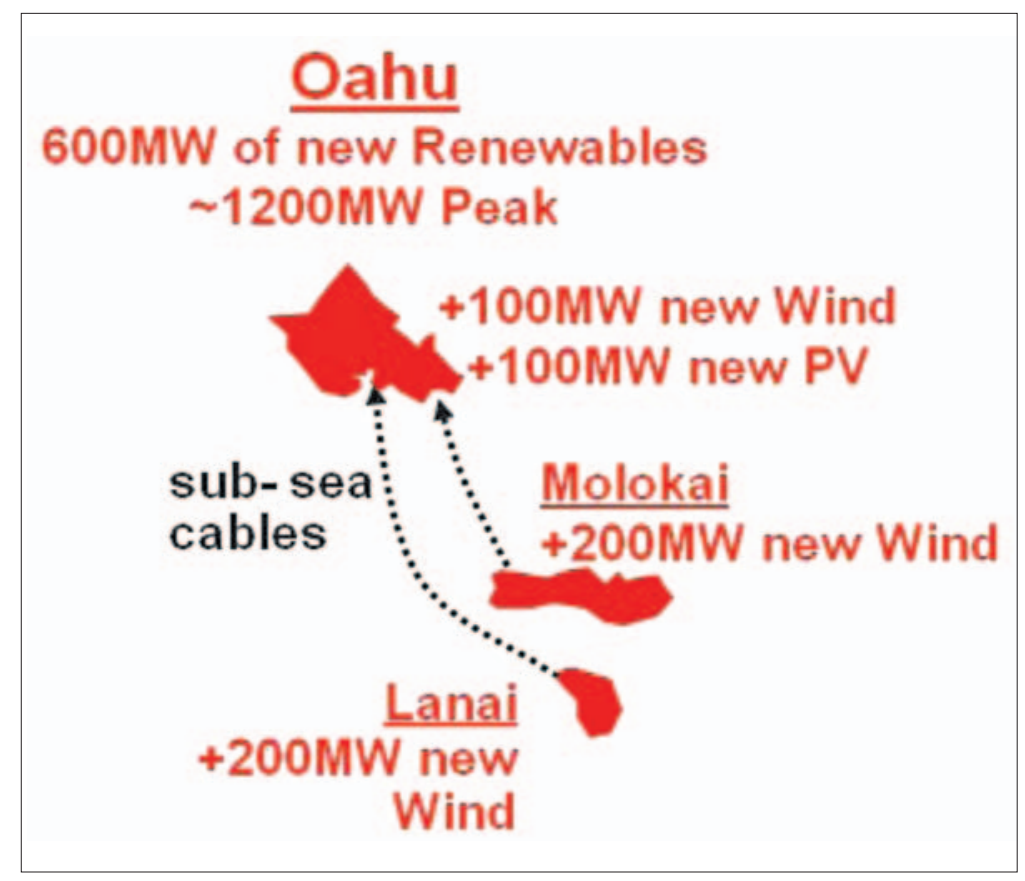

Figure 2. Map of Oahu, Molokai, and Lanai showing electricity potential from wind and photovoltaic generation. 


\section{HECO Grid Background and Baseline Assessment}

Table 2 provides a list of key power plants on the island of Oahu. The Oahu system has a daily peak of about $1200 \mathrm{MW}$ and a daily minimum of about $600 \mathrm{MW}$. Total firm generation capacity on Oahu is 1,817 MW, with an average unit age of 43 years.

Baseload units run 24 hours a day, seven days a week, and follow load variations. These generating units have annual capacity factors in the range of 50\% to $60 \%$. Cycling units are on during the day and off at night (scheduled a day ahead). They run about 2,000 hours per year, with about 300 starts per year. Peaking units run in the range of 500 to 1500 hours per year. All units are on regulation except the 46-MW H-POWER plant. Independent power producer (IPP) units are the most economical, so they are run first-HECO baseload units cycle down at night, while IPP units continue running at a high level. Because of the characteristics of the island power system, the reserve margin is about twice that of an interconnected system. The target loss of load probability is 1 day in 4.5 years. An evaluation was done to better characterize the ramping and other flexibility capabilities of the HECO units.

\begin{tabular}{|c|c|c|}
\hline PLANT & CAPACITY (MW) & FUEL RESOURCE \\
\hline HONOLULU & 113 & OIL (LSFO) \\
\hline WAIAU & 499 & OIL (LSFO) \\
\hline KAHE & 651 & OIL (LSFO) \\
\hline CIP & 120 & OIL (DIESEL/BIODIESEL) \\
\hline H-POWER (IPP) & 46 & REFUSE \\
\hline KALAELOA (IPP) & 208 & LSFO \\
\hline AES-HAWAII & 180 & COAL \\
\hline TOTAL FIRM GENERATING CAPACITY & & 1,817 \\
\hline
\end{tabular}

Generation is located primarily in the west portion of Oahu, whereas loads are largely in the east, which results in a primary power flow direction from west to east (see Figure 3). An evaluation identified a potential of $100 \mathrm{MW}$ of wind resource on the island of Oahu, and HECO is working with the industry to investigate and reliably tap this on-island potential.

HECO's study included the evaluations described below of generators, reheat-unit recycling, transmission infrastructure, and dynamic studies. 


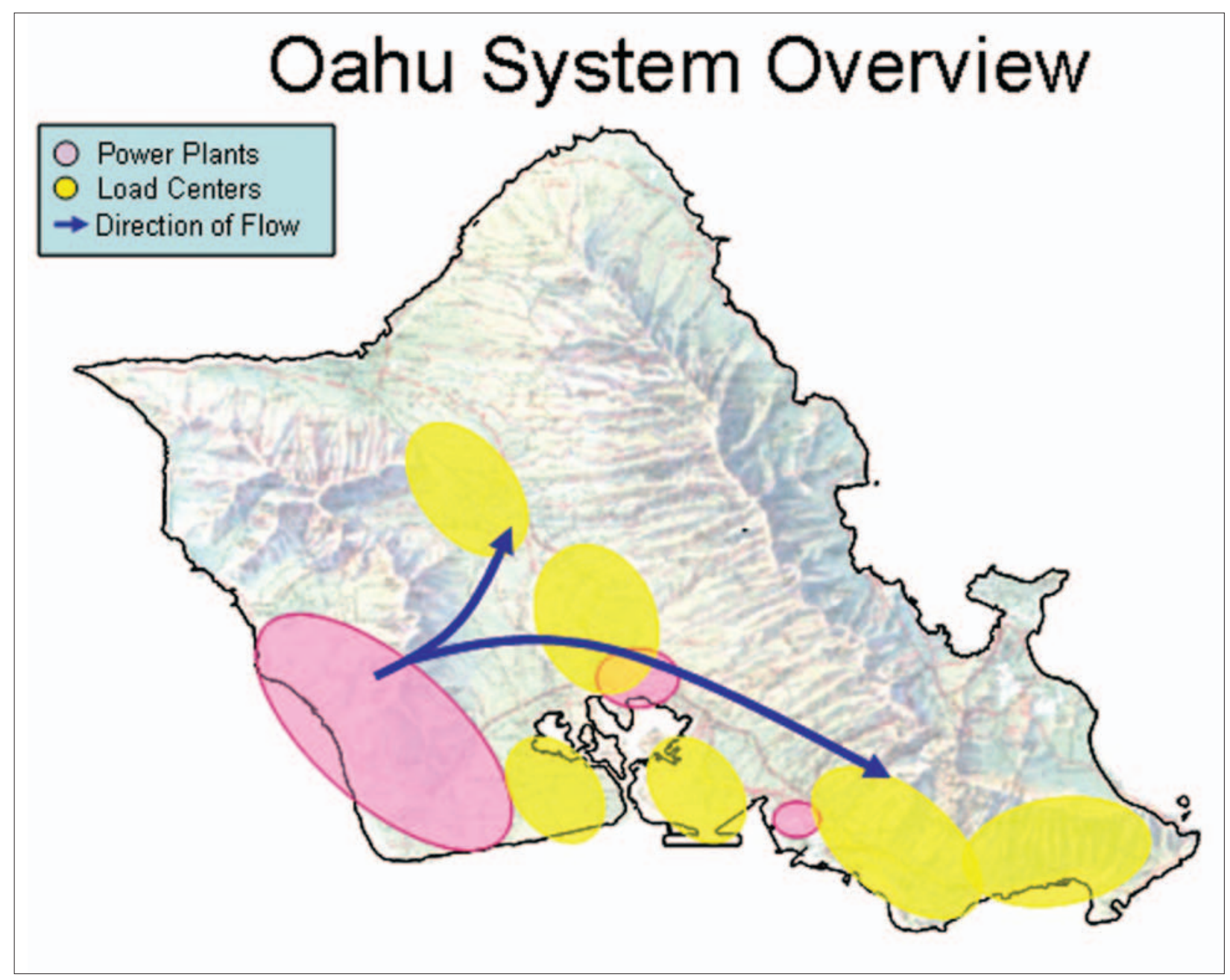

Figure 3. Overivew of Oahu system showing primary electrical flow direction from the west side of the island, location of majority of power plants, to the east side, and primary load centers.

\section{HECO GENERATOR STUDIES}

HECO studied how to improve the dynamic response of their existing generators. Their work included developing generating units' specific control logic to increase unit ramp rates, characterizing the existing governor droop response on HECO generators, tuning units for improved dynamic response and ensuring a uniform droop response for all regulating units connected to the grid. A key focus was to increase the ramp rates of the existing units to accommodate more variable renewable energy on the system. Testing was conducted for each generic design and size steam unit to prove the functional capability and identify equipment constraints. Control logic is being developed for each steam unit. These improvements to dynamic response will provide sufficient regulating capability to allow $500 \mathrm{MW}$ of wind and $100 \mathrm{MW}$ of solar PV energy to be integrated into the Oahu electrical system without constraining wind farm ramping and with minimal curtailment of the renewable resources. 
Additionally, HECO contracted with KEMA to evaluate the operation and design configuration of HECO's Energy Management System (EMS), including automatic generation control (AGC) and SCADA for higher penetrations of variable generating and distributed resources. Modeling and tuning of the system was completed.

Evaluation of the AGC system identified improvements in stability and responsiveness. The results of the AGC tuning were inputs to the AGC models in the GE study, as was the dynamic response work.

Recommendations from the model study include:

- Increase the frequency of the AGC cycle from 10 seconds to 2 or 4 seconds.

- Change the load increase / decrease signal from a fixed-pulse width to set-point control or, alternatively, to a variable-width pulse. It is currently a 200-millisecond pulse width.

- Sustain central EMS control during major frequency deviations and eliminate the use of the local frequency control unit at each generating unit.

HECO staff will be working with generator industry experts to evaluate the value and potential long term operating impacts of these recommendations on unit life, long-term performance and maintenance costs associated with more aggressive and "up-anddown" operations.

\section{OPERATIONAL FLEXIBILITY STUDY}

HECO completed a study of its base loaded reheat units to determine various modes of modified operation including daily on/ off cycling, weekend on/off cycling, long-term on/ off cycling, load cycling to lower minimum loads, and turbine full speed no load operation. Two of the eight existing baseload reheat units were tested for some of these operating modes during the course of the study. As with the other two HECO studies, the results of the reheat analysis provided inputs to the GE modeling study. It was determined that load cycling to lower minimum loads in conjunction with the faster ramping capability provided the most benefit. The results of these simulation studies need to be further investigated, but initial findings show potential gains in wind farm capacity factors and also show that regulating reserve improvements can contribute to better system frequency control that can help counter the short-term variability of wind and solar resources.

\section{TRANSMISSION INFRASTRUCTURE}

HECO assessed potential cable landing sites and transmission corridors. The evaluation included a system overview, HECO transmission assumptions, and options for cable landing sites and transmission corridors. 


\section{DYNAMIC STUDIES}

The EPS study evaluated the existing system and current operating practices. The work included evaluating transient stability issues on the existing system and contingency conditions on the proposed high-voltage direct-current (HVDC) cable configurations. Reliability criteria (e.g., allowable load shed, stability, voltage criteria) were developed for the HECO system with the new HVDC interconnection. The overall goal is to ensure that reliability is maintained.

A baseline of the current system with existing operating practices was established by identifying the impacts of wind generation at peak, off-peak, and shoulder periods. Transient stability issues were expected to be a possible critical factor as wind generation is increased on the existing HECO system and as faults and unit losses are introduced into the model. EPS focused on the current system and did not do an optimization. The baseline model developed by EPS served as a starting point in the GE work, with potential mitigation measures identified to improve the system performance.

For analysis of fault conditions, the HVDC transmission system mirrored the contribution of the wind turbine. This modeling approach was used because the fault current varies with each manufacturer, and it is a very conservative assumption because fault current is reactive and HVDC does not transmit reactive power. The EPS analysis focused on the HECO side of the system. The interaction between the wind turbine controls and HVDC controls is an important issue to be addressed in future design studies.

EPS studied peak, valley, and off-peak load cases. In many of the cases, the proposed improvements to the load-shedding settings were important to system reliability. The largest contingency studied was the loss of a 200-MW HVDC line, then the loss of the following generators: AES (180 MW), Kahe 5 (142 MW), and Kalaeloa CT 1 (84 MW).

The frequency plot analysis further supported the benefits of the proposed load-shedding revisions, including the addition of a kicker block. The PSS/E application was used to model the rate of change of angle at the buses, resulting in about a 7-cycle relay delay. This delay is not expected to be a problem because electrically it is a very tight system. Although the analysis showed that the system can be stressed further than previously thought, there are still limits and cost implications on the existing system. System performance can be significantly improved by using inertial response in the wind turbines. Additionally, a case was examined where the system is stable but units on the weak side of the system are stressed and oscillating against each other.

The power flow results from the EPS analysis are within the planning criteria. The alternating-current $(\mathrm{AC})$ inverter bus voltage and reactive power output sensitivity show that although the inverter can help with some reactive power, something else is needed. There does not appear to be a stability constraint due to the future wind generation, but there could be an issue of sufficient inertia. The spinning reserve is adequate. Although inertial response from wind turbines has some limitations (e.g., 
it is important not to stall the wind turbines), there can be considerable inertial response available from wind generators during high wind, which is when the inertial response is needed. Overall, the analysis incorporates many conservative assumptions and indicated no major transient stability problems on the grid. It is recommended that wind turbines with an option to supply inertia to the grid be considered for the project.

\section{HAWAIIAN ISLANDS TRANSMISSION INTERCONNECTION PROJECT}

This section describes the initial study of interconnection of transmission systems done by R.W. Beck, as well as the expansion of this work by Electranix.

\section{INITIAL ASSESSMENT}

In 2008, the U.S. Department of Energy contracted R.W. Beck to evaluate interconnection of the transmission systems of the islands of Lanai, Molokai and Maui with Oahu. This independent review included an initial evaluation of the technical configuration of establishing an undersea cable system and examining impacts to the existing electric transmission systems as a result of interconnecting the islands.

\section{INTERCONNECTION STUDY}

To move forward from the foundational work of the R.W. Beck report and to support the Hawaiian Clean Energy Agreement, DOE contracted with Electranix Corporation through NREL. Electranix studied the undersea cable system necessary to transmit $400 \mathrm{MW}$ of wind power from the islands of Lanai and/ or Molokai to Oahu (Stage 1) and the future installation of a 200-MW-capacity cable system to interconnect the island of Maui (Stage 2).

The study included a technical feasibility assessment and budgetary cost estimate of the undersea transmission interconnect options. Inputs have been provided from the suppliers of undersea power cables and DC converter stations. Building on the R.W. Beck study, 18 alternative configurations were developed, and six DC cable options and one AC cable option were selected for further study. Only one of the selected options included undersea cable transmission between Lanai and Molokai, whereas all the alternatives from the previous study included undersea cable transmission between the two islands. The economic justification for undersea cable transmission between Lanai and Molokai could not easily be established, so the feed to Oahu from these islands was radial only.

The AC option was only considered viable if three-core cross-linked polyethelene (XLPE) cables can be used; but this approach is limited by the depth to which the cable can be laid because of its weight. Consequently, AC cables cannot be used for feeding into Oahu. However, they could be used to interconnect Molokai and Lanai-and even to Maui, which was investigated for one option. For long AC undersea cables, the three-core XLPE cable is the most viable configuration because having the three-phase 
conductors as close together as possible results in significant cancellation of the magnetic field generated by the phase currents. Eddy current and other induced currents in the shield and armor conductors of the cable are minimized, allowing low induced cable losses. Alternatively, three separate single-core cables will result in higher losses in the shields and armors because there is no cancellation of the magnetic field generated by the phase currents unless the three cables are lashed and laid together.

The six DC options use voltage-sourced converters (VSCs), which can create a stable AC supply into which wind turbine generators can connect (see Figure 4). VSCs also offer a significant buffer to AC system faults at one end that adversely impact the AC system at the other end. The wind turbine generators on Molokai and Lanai will not be affected significantly by severe AC system faults on Oahu.

With a suitable control strategy for the VSC transmission, it will be possible to maintain a steady $\mathrm{AC}$ voltage and frequency for the sending-end wind farms. This means that a

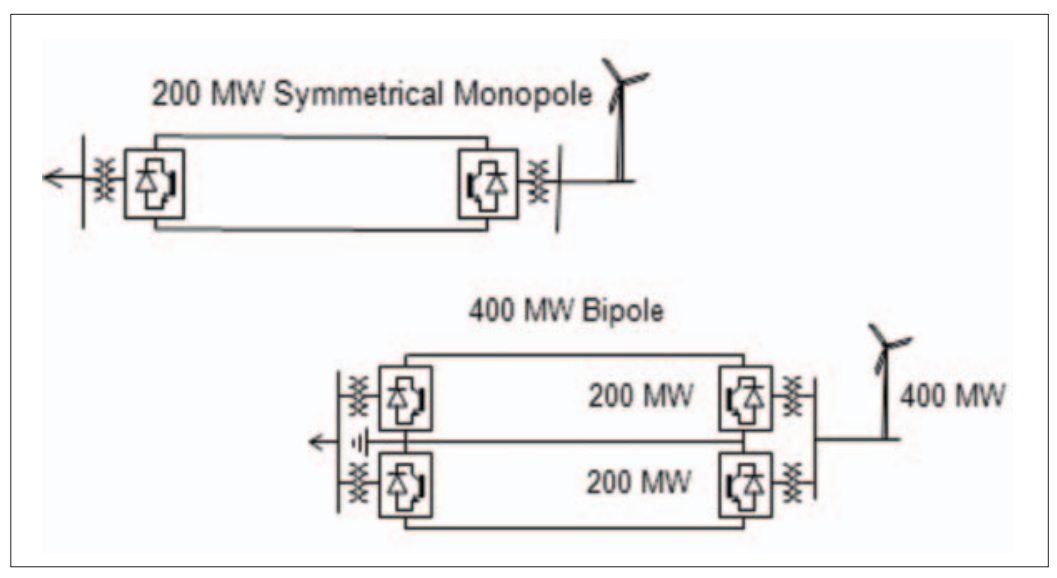

Figure 4. Schematic diagrams showing 200-MW symmetrical monopole and 400-MW bipole configurations.

direct and conventional interconnection to the small local load on Molokai or Lanai is possible, although the economics should be further evaluated. Only when the DC cable transmission is completely taken out of service would the interconnection to local load need to be transfer-tripped.

The level of power schedules into or out of the HECO system on Oahu is restrained to the maximum single-contingency outage possible - which, for this study, is $200 \mathrm{MW}$. Rating the converters and cables above this level is certainly possible and perhaps desirable, but needs to be further investigated.

From a technical perspective, the VSC cable transmission applied to these DC options is completely viable, with little risk of significant problems that would impede its use. The technology is being used in other projects of similar rating such as the BorWin Alpha 400-MW offshore wind farm in the North Sea. 
Three additional scenarios were developed for study leading to Stage 2, which looked at the connection to Maui. Essentially, the islands of Molokai, Lanai, and Maui are interconnected by AC cables in Stage 2, and as such, must be synchronized with each other. In the Stage 2 scenarios, the electric interconnection from Maui is terminated at Lanai and / or Molokai, rather than radial at 200 MW all the way to Oahu (see Figure 5). This scenario avoids a long undersea cable connection all the way to Oahu and allows an AC interconnection between the islands of Molokai, Lanai, and Maui.

The technical challenge in implementing the Stage 2 development based on a Stage 1 interconnection of VSC undersea cable transmission to Oahu from Molokai and Lanai is the following: synchronizing the wind farms on Molokai and Lanai and the power system on Maui together with the VSCs at Molokai and / or Lanai.

Stable synchronization is readily possible if one of the VSCs at Molokai and/or Lanai is operated with an independent clock that controls the frequency of the interconnected islands of Molokai, Lanai, and Maui. This means that the frequency of the three islands

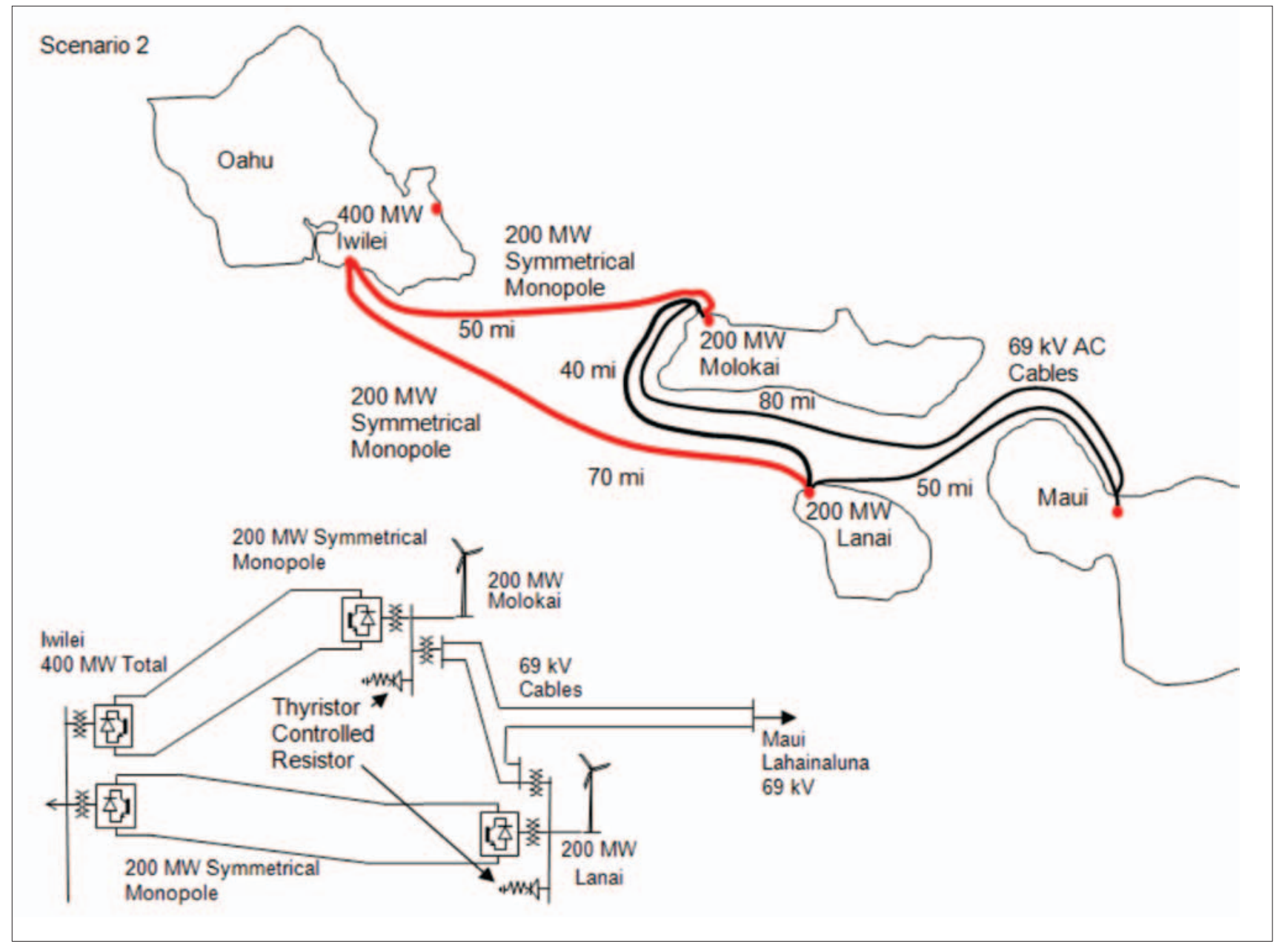

Figure 5. An illustrative Stage 2 scenario showing termination of electric interconnection from Maui at Lanai and/or Molokai, rather than radial at $200 \mathrm{MW}$ all the way to Oahu. 
is controlled very tightly to $60 \mathrm{~Hz}$. This scenario has its advantages, but suffers from lack of DC current control in the frequency-controlling VSC, with the possibility that it might be loaded to levels of undesired DC overcurrent that may exceed its rating. The frequency-controlling VSC can be a single-pole cable feeder-either a symmetrical monopole or one pole of a bipole- that acts without power control, not unlike a swing bus in an AC system.

To combat the possibility of DC overcurrent in the VSC that is synchronized with an independent clock, thyristor-controlled resistors will need to be applied near each VSC to absorb any power surges and provide time for transfer-tripping or power-down of the wind farms. This is to ensure that the VSC transmission to Oahu remaining in service is able to remain loaded within controlled limits. In addition, certain control measures can be undertaken to assist in preventing DC overcurrents.

This configuration operates satisfactorily when one of two VSC transmission poles or monopoles is synchronized with an independent clock and the other VSC transmission pole or monopole is synchronized with the more conventional phase-locked loop (PLL) operating off the AC interconnection busbar. If the VSC pole with the independent clock is removed from service, the other pole with the PLL control must switch immediately and automatically to independent clock operation to maintain frequency on Molokai, Lanai, and Maui.

The technical operation of the AC-cable-connected and synchronized Molokai, Lanai, and Maui systems and wind farms can work with the VSC transmission to Oahu if care is taken in specifying the requirements for the VSC controls. The HVDC equipment suppliers will be required to demonstrate that their control strategy will operate acceptably. The essential requirement of the VSC transmission control is to ensure that the wind turbine generators applied to the wind farms will operated satisfactorily.

\section{OAHU WIND INTEGRATION STUDY}

The key objective of GE's Oahu Wind Integration Study is to identify operational strategies and new technologies that could help enable high penetrations of renewable energy. The study quantified and prioritized the benefits of new operational strategies and technologies. Many of the solutions identified in the study are already being implemented by HECO.

A variety of tools, shown in Figure 6, are used across several time frames, including models for Positive Sequence Load Flow (GE PSLF), Statistical Wind Power Variability Assessments, and Multi-Area Production Simulations (GE MAPS). GE's PSLF has been developed and advanced to incorporate long-term dynamic simulations (AGC response in 2-second steps), which can be used to analyze events as they unfold over an hour. GE's MAPS incorporates inter-hour renewables variability analysis (10-minute steps) that flags hours throughout the study year that need to be examined further in the AGC model, while respecting the ramp rates within each hour. The modeling was time 


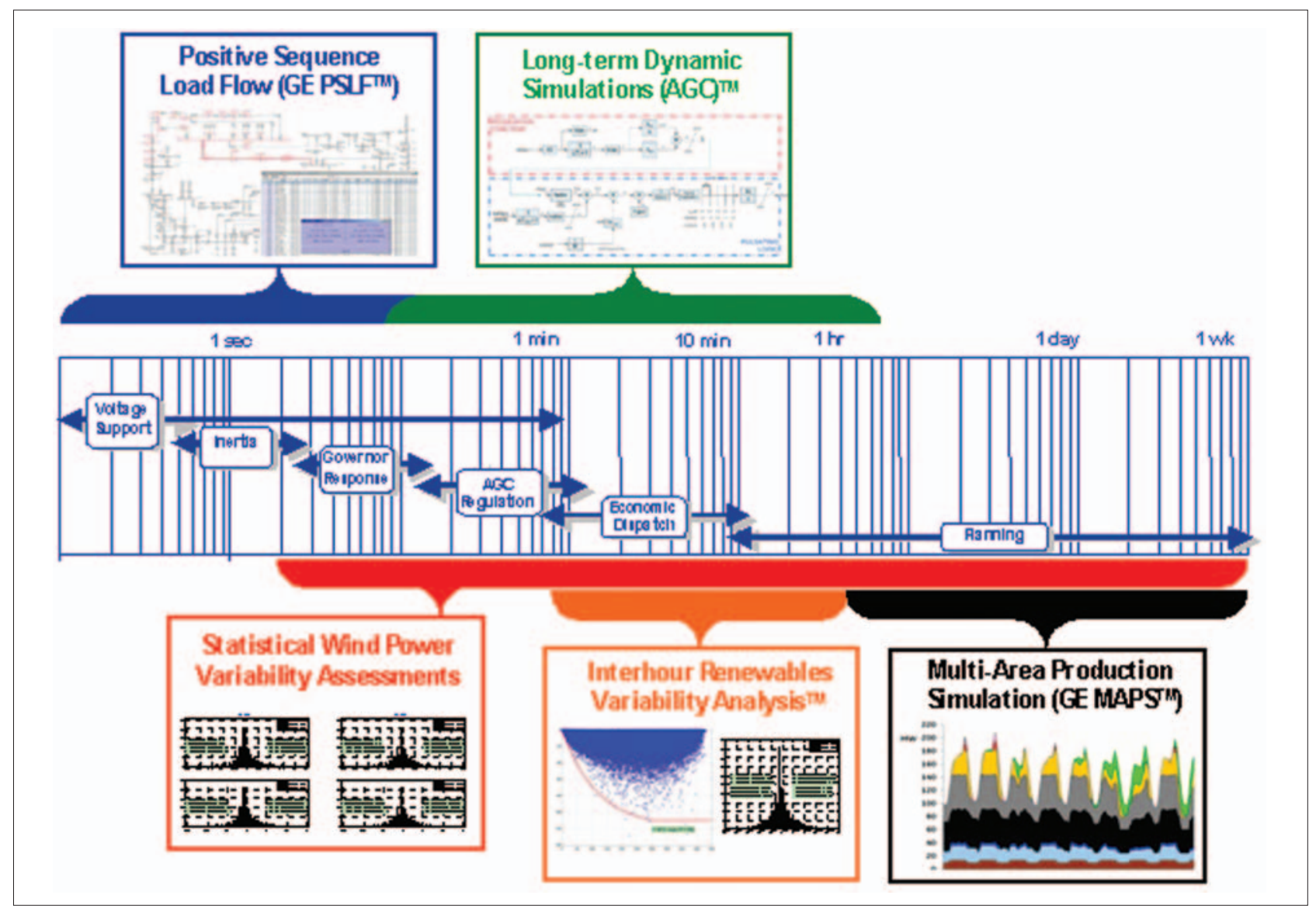

Figure 6. GE's Oahu Wind Integration Study used a variety of existing tools and developed new tools to assess system behavior across several time frames.

consuming because the details of every generator unit are critically important when modeling a small island system such as Oahu. The system model was dispatched with forecasted wind generation and then run with actual wind generation-with the difference being the reserves requirements.

The 2014 baseline model of Oahu's power system has a maximum hourly load of about 1,243 MW, a minimum hourly load of about $513 \mathrm{MW}$, and annual energy of about 7,800 gigawatt-hours (GWh). In the dynamic sub-hourly modeling in GE PSLF, all AGC is centrally controlled, based on the KEMA study work; there is no local frequency control. A conservative assumption is the change of Oahu's quadratic frequency-dependent model to a linear dependence of real power to frequency. Overall, many of the changes to the model are forward looking, and most simulations were run both as the system is today and as it is anticipated to be in the future. HECO has been able to increase the ramp rate on their existing generators by a factor of about three. The Oahu wind plants were modeled as full-converter wind turbines.

The analysis focused on the base case and three of the scenarios: the 2014 Baseline, Scenario 1 (Big Wind-Oahu only), Scenario 3 (Big Wind-Oahu and Lanai only), and Scenario 5 (Big Wind-Oahu, Lanai, and Molokai). These three scenarios were analyzed 
to determine the unit commitment/ dispatch, identify new operating characteristics, and establish a base from which to evaluate strategies to enhance operation with high penetrations of variable generation from renewables.

- The Scenario 5 model was developed from the 2014 Baseline model by adding $100 \mathrm{MW}$ of Oahu wind generation, $200 \mathrm{MW}$ of Lanai wind generation, $200 \mathrm{MW}$ of Molokai wind generation, and $100 \mathrm{MW}$ of Oahu photovoltaic generation (see Table 1, Scenario 5). Cases were run first with no modification to unit commitment or up-reserve (5A-no wind forecast included), and then cases were run that included a wind power forecast (4 hour) in the unit commitment and refined the up-reserves (5B - based on expected wind variability). The second set of cases was originally run with $40 \mathrm{MW}$ of effective down-reserves; $90 \mathrm{MW}$ were later determined to be needed/adequate. The second set of cases (5B) resulted in significantly less curtailment of available annual wind energy on Molokai and Lanai (about 15\%, compared with about $21 \%$ ).

- The Scenario 1 model was developed from the 2014 Baseline model by adding $100 \mathrm{MW}$ of Oahu wind generation and $100 \mathrm{MW}$ of Oahu photovoltaic generation (see Table 1, Scenario 1). This scenario is operated in a manner similar to scenario 5B (wind power forecasts in the unit commitment and refinements to the up-reserves based on expected wind variability). No solar forecasts are included in any of the cases. This scenario resulted in no wind curtailment.

- The Scenario 3 model was developed from the 2014 Baseline model by adding $100 \mathrm{MW}$ of Oahu wind generation, $400 \mathrm{MW}$ of Lanai wind generation, and $100 \mathrm{MW}$ of Oahu photovoltaic generation (see Table 1, Scenario 3). This scenario is also operated in a manner similar to scenario $5 \mathrm{~B}$, and there are similar levels of wind curtailment in scenarios 3B and 5B. Scenario 3B had higher sub-hourly variability due to the co-location of the off-island wind projects, resulting in slightly higher reserve requirements. The use of contingency reserves was still not required; a good ramp forecast will be needed to manage the reserves.

GE developed and analyzed additional mitigation strategies to enhance the integration of renewables. Key strategies included:

- Wind power forecasting to improve unit commitment;

- Refine the up-reserve requirements;

- Reduce the minimum power of the baseload units;

- Seasonally cycle off some select baseload units;

- Reduce the reserve requirements by using fast-start units and load control; 
- Increase the thermal unit ramp-rate capability and enhancing the droop;

- Consider advanced wind turbine technologies such as inertia and frequency control.

Down-regulation is included in both advanced wind turbine technologies and in reduced minimum power of baseload units. In addition, some aspects of storage were examined (e.g., for implementing ramp-rate limits on wind plants).

Scenario $5 \mathrm{C}$ was developed from $5 \mathrm{~B}$ by reducing the minimum power on the HECO baseload units. The simulation of load-rejection events indicated that $40 \mathrm{MW}$ of downreserves could put the system at risk. Scenario $5 \mathrm{~F} 1$ was developed from $5 \mathrm{C}$ by increasing the down-regulation from about $40 \mathrm{MW}$ to about $90 \mathrm{MW}$. Scenario 5F2 was developed from $5 \mathrm{~F} 1$ by adding the seasonal cycling of three baseload units. An additional scenario was developed by adding a perfect solar forecast to 5F2. Scenario 5F3 was developed from $5 \mathrm{~F} 2$ by modifying the up-reserve requirement.

An analysis and comparison was done of the overall impact of the proposed mitigation strategies on the delivered renewable energy. The mitigation strategies evaluated in the scenario analysis captured 2,001 of 2,091 GWh of total available wind and solar energy; the remaining $90 \mathrm{GWh}$ of curtailment is mostly due to night-time minimum generation events.

Dynamic performance assessments validated feasible performance of the scenarios already analyzed and assessed technology and operational strategies that could help integrate wind and solar power in the sub-hourly timeframe. Additional strategiesincreased thermal ramp capability, enhanced droop, and advanced wind turbine technologies - were evaluated as part of the sub-hourly dynamic assessment.

Sub-hourly impacts were assessed for the following situations:

- Sustained drops in wind and solar power over an hour. The long-term (60-minute) analysis focused on the top-ten worst hours. Reserve requirements were adequate for slow sustained wind/solar drops.

- Sustained drops in wind and solar power within an hour. The targeted up-ramp adequacy is twice what would be just enough (i.e., twice what would be fully exhausted after 10 minutes). The largest drops in wind and solar power over 10-minute periods can be handled with the future improved AGC ramp rates-that is, two to three times the current ramp rates. Results indicate that the HECO steam units carry the burden of regulating system frequency as they are typically dispatched to lower operating loads and are positioned to respond to variable wind and solar resources.

- Rises in wind and solar power when thermal units are near their minimum power. Wind rise events can require timely (automatic) wind plant curtailment when the system is constrained on down-regulation. 
- Quick variation in wind and solar power within an hour, including analysis of the wind and solar data, variability sharing among thermal units, frequency performance and power variability sharing, and impact of wind plant ramp-rate limits. The storage required to implement the up/down ramp-rate limits at each wind plant is yet to be determined; the amount of energy curtailed in the down limits is a similar order of magnitude as that curtailed in the up limit. Load variability was not included in the analysis of the 1- and 5-minute timeframes; HECO's load has been relatively smooth because it is weather-based, with very few large industrial loads.

- Load-rejection events that occur when thermal units are backed down. Wind plants can provide fast response at a low cost for over-frequency (load-rejection) events.

- An HVDC cable trip event. Inertial response from the wind generators can significantly improve the frequency response and help to avoid under-frequency load-shedding. The cable VSC control strategy needs to include effective communication of the Oahu system frequency directly to the wind plants on Molokai and Lanai.

Overall, the GE study found that about 15\% of wind energy available on Oahu (postcable losses) is estimated to be curtailed if today's operating practices do not evolve to include wind power forecasting and refinement of the up-reserve requirements. With the proposed strategies, most of the available renewable energy will be accepted-about $4 \%$ of the available energy is curtailed (see Figure 7). Wind curtailment occurred at night-time light-load conditions.

The technical operational analysis found no limitations to the flexibility of either distributing the off-island wind generation between Molokai and Lanai or co-locating it on one of the two.

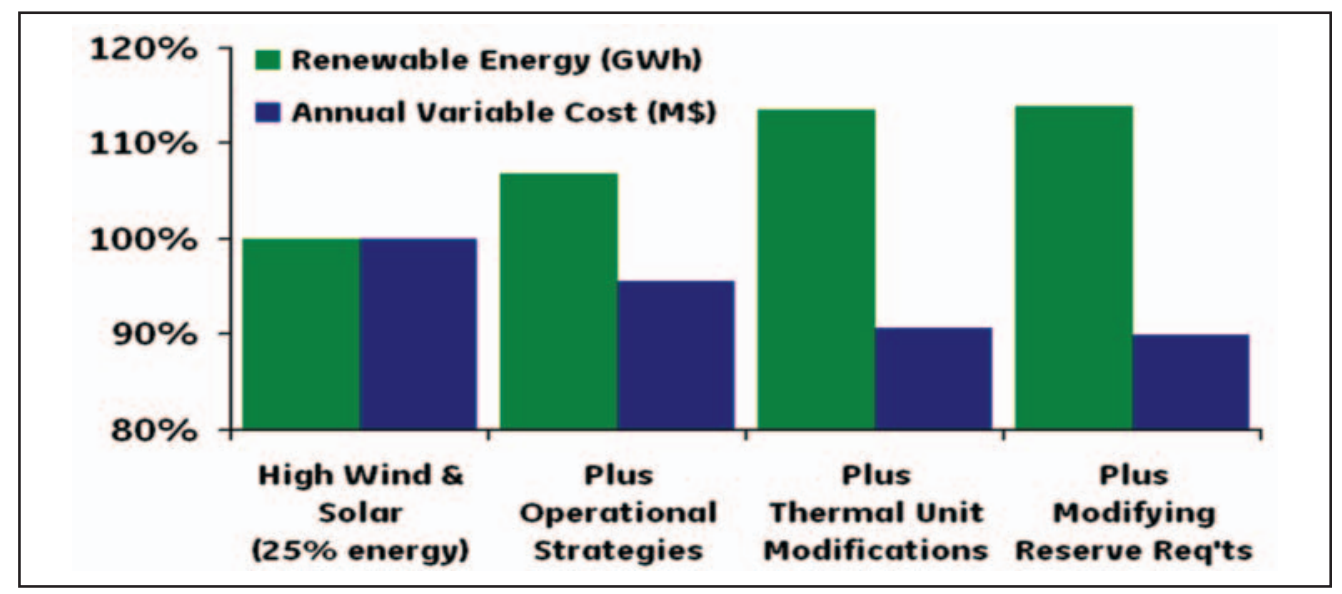

Figure 7. Comparison of four scenarios, showing increasing renewable energy and decreasing annual variable cost as operational strategies, thermal unit modifications, and modified reserve requirements are added to the base case. 


\section{RELATED WORK}

Related work to OWITS not included herein includes a comparison of PV and wind economics and an evaluation of cable finances.

\section{PV/Wind Comparisons}

The results indicate that it is not realistic for the proposed $400 \mathrm{MW}$ of Molokai/Lanai wind power to be replaced with Oahu solar power, but that both an aggressive solar deployment on all the Hawaiian Islands and the $400 \mathrm{MW}$ of Big Wind are needed to meet the $40 \%$ renewable by 2030 HCEI goal.

\section{Cable Finances}

Initial work on the economics of the Big Wind and the cable projects is under way, including key tasks to build a business case for Big Wind and the framework for a net present value model to evaluate economics. Initial financial analysis includes studying costs for on-island infrastructure needed to support the cable system and identifying key financial issues.

\section{SUMMARY AND FUTURE WORK}

The HCEI is an ambitious program to develop and implement renewable energy and energy efficiency for the state of Hawaii. Realizing the goals of HCEI requires detailed technical analysis of the electrical grid operations on the various islands and closely coordinated work between renewable energy analysis, transmission expansion studies, and analysis of the electrical grid operations by the various utilities and cooperatives in Hawaii.

The OWITS project is an important step in furthering the understanding of Big Wind initiatives and evaluating the different options for an undersea cable. Future work that builds off the results of OWITS will include the following:

- Evaluate cable financing options and determine business ownership model for cable and how it will be operated

- Develop detailed bid specifications that can be used to implement both undersea cable and wind plant projects either turnkey together or as separate bids implemented in close coordination 
- Further evaluate cable siting, environmental permitting, and EIS requirements

- Proceed with funding studies and work with Public Utilities Commission to determine impact on ratepayers

In addition to the work described above, additional renewable integration and transmission studies are being undertaken for all of the Hawaii Islands to further examine the path forward to meeting the HCEI goals.

\section{REFERENCES}

1. R.W. Beck, "Hawaii Inter-Island Cable Study," Draft report to the U.S. Department of Energy, May 2009.

2. Hawaiian Electric Power Facts — http://www.heco.com/vcmcontent/StaticFiles/pdf/ PowerFacts_6-2010.pdf

3. Electranix, Oahu Wind Interconnection and Transmission Study (OWITS) Hawaiian Islands Transmission Interconnection Project, November 2010.

4. AWS Truepower, "Development of Regional Wind Resource and Wind Plant Output Data Sets for the Hawaiian Islands," June 2010.

5. General Electric, Sebastian Achilles, Krishna Anaparthi, Harjeet Johal, Gene Hinkle, Devon Manz, Shakeer Meeran, Nicholas Miller, Wei Ren; “Oahu Wind Integration Study," November 2010.

6. Hawaii Clean Energy Initiative - www. Hawaii Clean Energy Initiative.org 


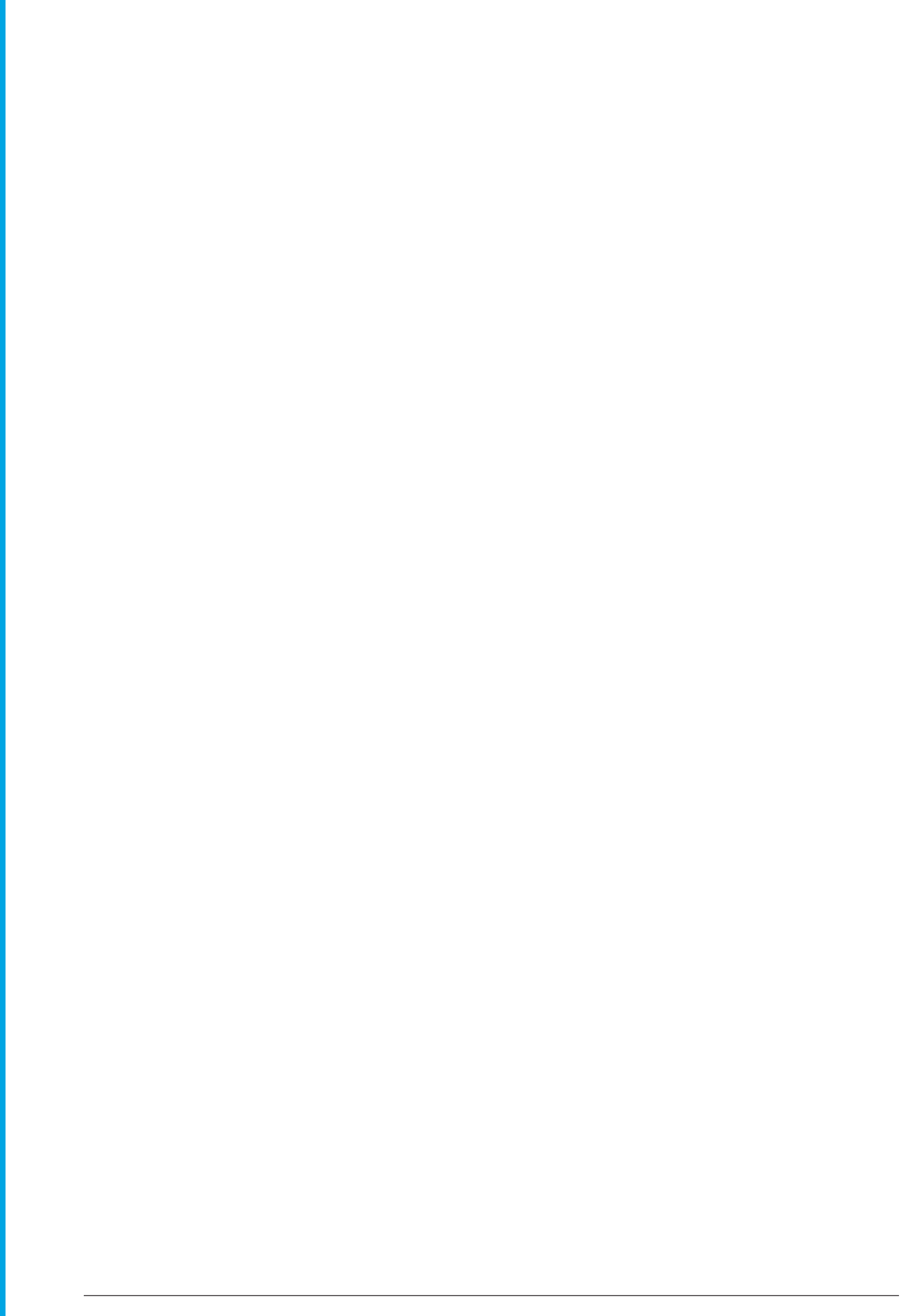




\section{REPORT DOCUMENTATION PAGE}

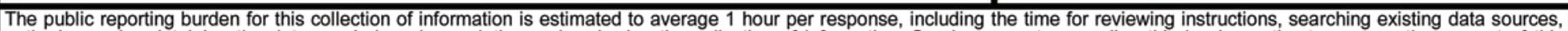

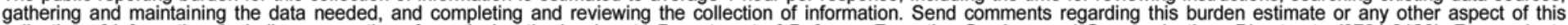

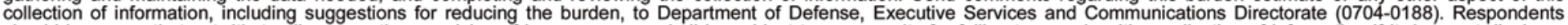

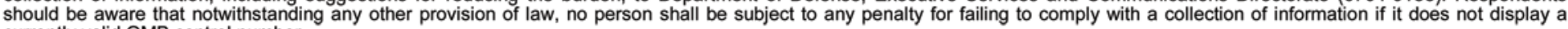
currently valid OMB control number.

PLEASE DO NOT RETURN YOUR FORM TO THE ABOVE ORGANIZATION.
1. REPORT DATE (DD-MM-YYYY)
2. REPORT TYPE
November 2010
TP
3. DATES COVERED (From - To)
$2008-2010$

4. TITLE AND SUBTITLE

OAHU WIND INTEGRATION AND TRANSMISSION STUDY:

SUMMARY REPORT 5a. CONTRACT NUMBER

DE-AC36-08GO28308

5b. GRANT NUMBER

5c. PROGRAM ELEMENT NUMBER

5d. PROJECT NUMBER

NREL/TP-5500-48632

5e. TASK NUMBER

IDHW.9173

5f. WORK UNIT NUMBER
7. PERFORMING ORGANIZATION NAME(S) AND ADDRESS(ES)

National Renewable Energy Laboratory

1617 Cole Blvd.

Golden, CO 80401-3393
8. PERFORMING ORGANIZATION REPORT NUMBER

NREL/TP-5500-48632

9. SPONSORING/MONITORING AGENCY NAME(S) AND ADDRESS(ES)

10. SPONSOR/MONITOR'S ACRONYM(S) NREL

11. SPONSORING/MONITORING AGENCY REPORT NUMBER

12. DISTRIBUTION AVAILABILITY STATEMENT

National Technical Information Service

U.S. Department of Commerce

5285 Port Royal Road

Springfield, VA 22161

13. SUPPLEMENTARY NOTES

14. ABSTRACT (Maximum 200 Words)

This study was composed of several smaller studies done in cooperation with other local entities and experts, all of which are summarized in this report.

15. SUBJECT TERMS

Hawaii; operational flexibility; Big Wind; dynamic studies; HECO; HCEl; grid; interconnection; island; undersea cable; generator; Electranix.

16. SECURITY CLASSIFICATION OF:

a. REPORT

Unclassified

\begin{tabular}{|c|c|}
\hline b. ABSTRACT & $\begin{array}{c}\text { c. THIS PAGE } \\
\text { Unclassified }\end{array}$ \\
Unclassified
\end{tabular}

17. LIMITATION OF ABSTRACT

UL
18. NUMBER OF PAGES 19a. NAME OF RESPONSIBLE PERSON

19b. TELEPHONE NUMBER (Include area code) 


\section{National Renewable Energy Laboratory}

1617 Cole Boulevard, Golden, Colorado 80401

303-275-3000 • www.nrel.gov

NREL is a national laboratory of the U.S. Department of Energy, Office of Energy Efficiency and Renewable Energy, operated by the Alliance for Sustainable Energy, LLC.

NREL/TP-5500-48632 • November 2010

Printed with a renewable-source ink on paper containing at least $50 \%$ wastepaper, including

$10 \%$ post consumer waste. 